\title{
Optimizations of friction stir welding of aluminum alloy by using genetically optimized neural network
}

\author{
Ibrahim N. Tansel • Mustafa Demetgul • \\ Hasan Okuyucu • Ahmet Yapici
}

Received: 20 November 2008 / Accepted: 9 August 2009/Published online: 26 August 2009

(C) The Author(s) 2009. This article is published with open access at Springerlink.com

\begin{abstract}
Genetically optimized neural network systems (GONNS) was developed to simulate the intelligent decision-making capability of human beings. After they are trained with experimental data or observations, GONNS use one or more artificial neural networks (ANN) to represent complex systems. The optimization is performed by one or more genetic algorithms (GA). In this study, the GONNS was used to estimate the optimal operating condition of the friction stir welding (FSW) process. Five separate ANNs represented the relationship between two identical input parameters and each one of the considered characteristics of the welding zone. GA searched for the optimized parameters to make one of the parameters maximum or minimum, while the other four are kept
\end{abstract}

\section{N. Tansel}

Mechanical Engineering Department,

Florida International University,

10555 West Flagler Street,

Miami, FL 33174, USA

\section{Demetgul ( $\bowtie)$}

Mechanical Department, Technical Education Faculty,

Marmara University,

Goztepe,

Istanbul, Turkey

e-mail: mdemetgul@marmara.edu.tr

H. Okuyucu

Faculty of Technical Education, Gazi University,

Besevler,

06500 Ankara, Turkey

\section{A. Yapici}

Engineering Faculty, Mechanical Engineering Department,

Mustafa Kemal University,

Iskenderun,

Hatay, Turkey

e-mail: ayapici@mku.edu.tr within the desired range. The GONNS was found as an excellent optimization tool for FSW.

Keywords Optimization · Neural network .

Genetic algorithm · GONNS · Friction stir welding

\section{Introduction}

Friction stir welding (FSW) bonds metal plates with the heat created by friction of a rotating tool to the surfaces. FSW may be used to bond aluminum, copper, and titanium alloys as well as the steel plates [1-10]. During the welding process, FSW does not require protective gas for shielding or electrodes to create an arc. Compare to other welding processes, FSW is a safer and a more economical method. There is no eye or excessive heat protection requirement from strong electric arc, powerful ventilation is not needed to remove toxic gasses, and costly safety measures are not need against fire hazard of melted metals violently coming out of the bonded area [11-19]. All these advantages encouraged aerospace, marine, and food processing industries to employ FSW in the manufacturing operations. In this study, feasibility of using a computer program with human-like learning and optimization capability was evaluated for selection of the optimal operating conditions to obtain the desired mechanical and metallurgical characteristics at the welded areas.

Instead of developing analytical or empirical models, use of artificial neural networks (ANN) were proposed as a third option a long time ago and have been used for many applications from speech recognition to classification of military targets [20-27]. Among the different ANN algorithms, backpropagation (BP) type ANN [20] is the most commonly used. Genetic algorithm (GA) [28-34] was developed by mimicking the natural evaluation process. 


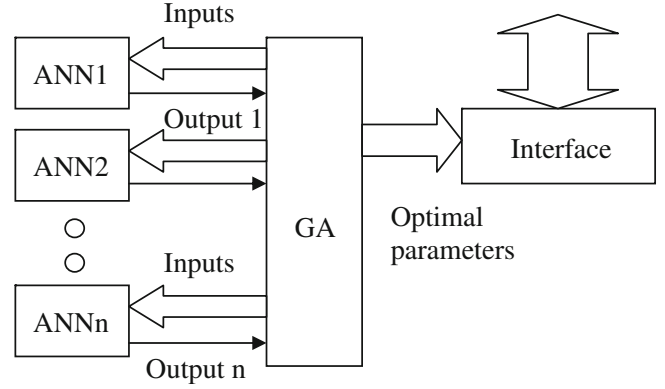

Fig. 1 Genetically optimized neural network system

Although the GA is slow, many researchers prefer this approach since it can optimize large number of parameters; it may effectively use multiple processers, and convergence probability to local minimums is very low. Tansel et al. [32, 34] introduced the genetically optimized neural network system (GONNS) by using ANN and GA together. GONNS model the system by using ANNs from the experimental data or observations. The optimal operating conditions are estimated by using the GA. The main advantage of the GONNS is ease of adaptation to any application as long as the ANNs can represent the system.

In the following sections, the theoretical background will be outlined very briefly. The proposed method, experimental data collection, and the results will also be presented in the following sections.

\section{Theoretical background}

The ANN, GA, and GONNS are very briefly reviewed in this section since the readers can find detailed information in literature and may use the toolboxes of commercial software.

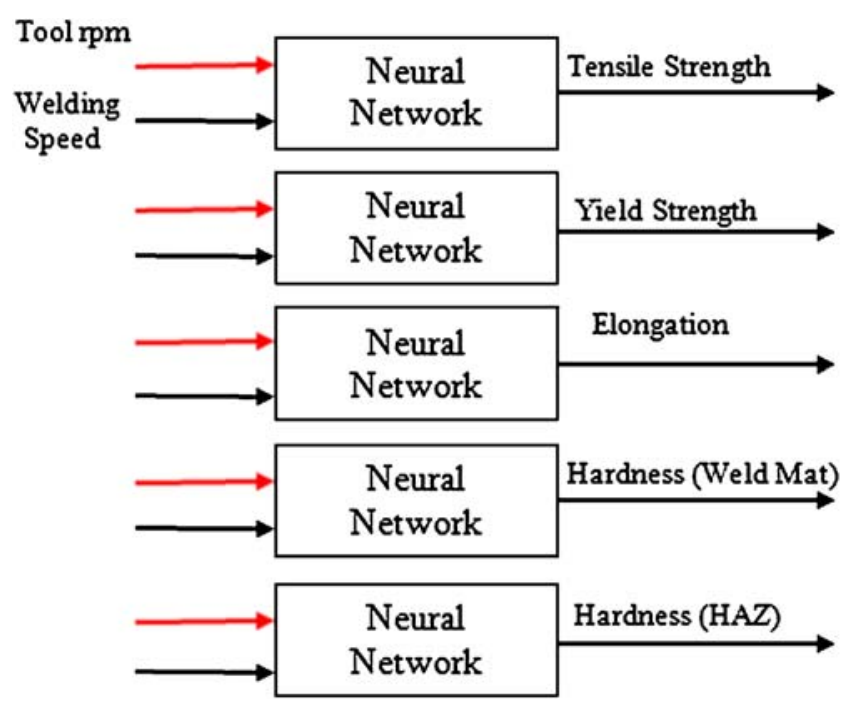

Fig. 2 Five artificial neural networks for representation of the friction stir welding operation

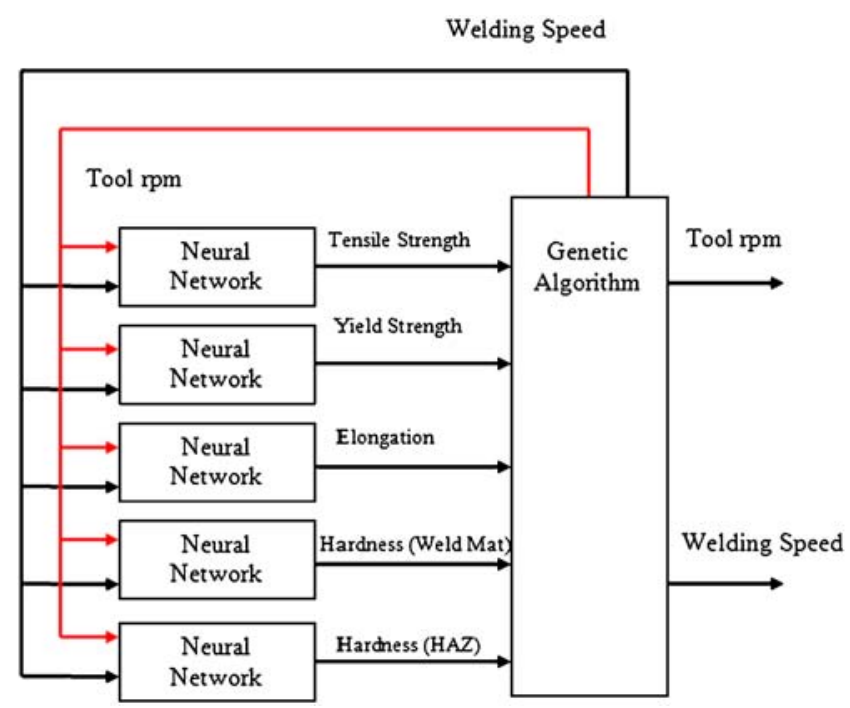

Fig. 3 Genetically optimized neural network structure

ANNs may be classified as supervised or unsupervised depending on the learning process [20-27]. The best known ANN algorithm is BP [20-23]. Neurons are generally located on three layers. The number of the neurons at the first and the last layer are equal to the inputs and outputs of the ANN. The user determines the number of neurons at the intermediate layer (hidden layer) with trial and error. In most of the BP applications, each neuron is connected to all the neurons of the following layer. Each neuron has a weight and nonlinear component to let it make the yes/no decisions. The supervised neural networks such as BP [20] require training before it is used for mapping or classification purposes. During the training, BP calculates the weights of the ANN to represent the relationship between the inputs and outputs. Unsupervised neural networks may start classifying the inputs without a separate training session; however, they may not be used for mapping purposes. BP is a perfect fit for modeling applications as long as there are no excessive amounts of abrupt changes in the characteristics of the input-output relationship of the system. User selects the number of the input and output nodes by considering the system. The number of the hidden nodes is selected either by experience or the best one is chosen after several models are fitted by considering the

Table 1 Genetically optimized neural network training ranges

\begin{tabular}{lc}
\hline Speed (rpm) & $500-1,500$ \\
Weld speed (mm/min) & $6.25-20$ \\
Tensile strength $(\mathrm{MPa})$ & $75-115$ \\
Yield strength $(\mathrm{MPa})$ & $45-90$ \\
Elongation (\%) & $3-12$ \\
Hard (weld metal) & $21-29$ \\
Hard (weld metal) & $23-29$ \\
\hline
\end{tabular}


Table 2 The chemical composition of aluminum alloy (Al1080) in weight percent [4]

\begin{tabular}{|c|c|c|c|c|c|c|c|c|c|}
\hline $\mathrm{Al}$ & $\mathrm{Zn}$ & $\mathrm{Cu}$ & $\mathrm{Ti}$ & $\mathrm{Cr}$ & $\mathrm{Mg}$ & $\mathrm{Fe}$ & $\mathrm{Ni}$ & $\mathrm{Mn}$ & $\mathrm{Si}$ \\
\hline & 0.0029 & 0.0039 & 0.013 & 0.0062 & 0.006 & 0.15 & 0.0034 & 0.0059 & 0.00115 \\
\hline
\end{tabular}

estimation accuracy and benefits of small network size. The learning rate and momentum may be gradually reduced to estimate the parameters of the ANN as accurately as possible without converging to local minimums. The training of the BP is a very tedious process, but even with very limited data, we obtained reasonable models for estimation of the system output [26].

GA was developed by considering the biological evolution process [28-34]. The algorithm represents all the parameters and switches with single binary string called chromosome. The size of the chromosome depends on the number of parameters, desired resolution, and switches. GA creates a population with the same size chromosomes and tries to perfect it by using the natural selection and survival of the fittest principles [28-34]. The user determines the population size, the number of children for each set of parents, and the probability of mutation by considering the characteristics of the problem. The GA creates the chromosomes randomly for the first generation in most of the applications. The chromosomes are perfected with the following steps: (1) selection of the mating parents, (2) selection of the hereditary chromosomes from the parents, (3) gene crossover, (4) gene mutation, and (5) creation of the next generation.

The GONNS use the BP type ANNs to model the relationship between the inputs and the outputs of the considered system. Generally, we select to have one output when we use the BP method to represent the system as part of the GONNS. Separate ANNs are used for estimation of each output. After the training of the ANNs, GA uses them to find optimal solutions. Our GONNS program was developed to try to minimize or maximize one of the outputs, while the other outputs are kept at the desired ranges. GONNS may be operated either in the single or in the multiple cluster modes. Each cluster has multiple ANNs and one GA. Depending on the problem, GONNS may be used in single or multi-cluster modes. Single cluster mode was used in this study. If we wanted to compare the performances of different materials, separate clusters would be used for each material. The block diagram of the single cluster model is presented in Fig. 1.

\section{Proposed procedure}

GONNS was proposed for modeling and optimization of the FSW. One GA was used for searching the optimal tool rotation speed and feed rate by using five ANNs represent- ing the FSW operation. In the previous study [4], single neural network with two inputs and five outputs was used to obtain a compact representation. Five separate neural networks with two identical inputs (tool rotation speed and feed rate) estimated the mechanical and metallurgical properties of the welding process. Generally, assignment of each output to separate ANN improves the accuracy of the models, which allow for using less number of hidden nodes, and reduce computational problems encountered at large networks. The ANN-based model of the stir welding process is presented in Fig. 2.

One GA was used for searching the optimal tool rotation speed and feed rate by using the five ANNs, which represent the stir welding operation. During the search, one of the five outputs was maximized or minimized, while the other four parameters were kept within the desired range. The block diagram of the GONNS for this problem is presented in Fig. 3. The full ranges of the input and the output parameters used in this study are listed in Table 1. User may use the full range or may ask the GONNS to keep the parameters within any boundaries as long as they are in the defined ranges of the parameters in Table 1.

\section{Experimental work}

Experimental data was collected during the stir welding of two hot rolled aluminum plates (Al 1080) with the dimensions of $5 \times 50 \times 150 \mathrm{~mm}$. The diameter of the rotating tool was $20 \mathrm{~mm}$. The chemical composition of the plates is presented in Table 2. During the welding process, the plates were clamped to a vice. The diameter of the rotational tools was $20 \mathrm{~mm}$. The plunge depth was selected as $4 \mathrm{~mm}$. A simplified diagram of the stir welding process is presented in Fig. 4. The tool speeds were selected as 500, 800, 1,000, 1,250 , and $1,500 \mathrm{rpm}$ in the tests. Plates were moved at $6.25,10,16$, and $20 \mathrm{~mm} / \mathrm{min}$ feed rates (welding speed). The friction force was kept constant at $210 \mathrm{~N}$.

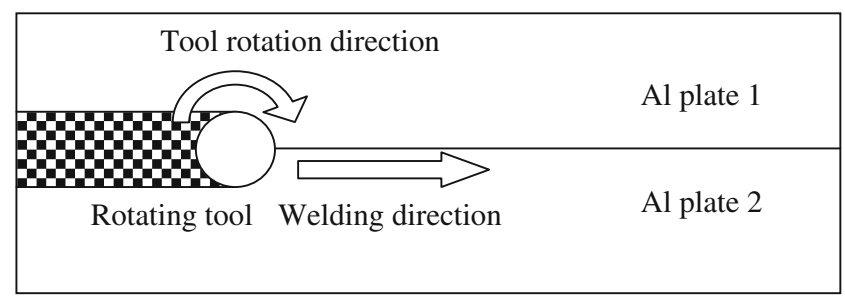

Fig. 4 The simplified diagram of the stir welding process 
Friction stir welded samples were cut with a diamond wheel saw. The welding zones of the test samples were characterized by mechanical tests and metallographic examinations [4]. Tensile and hardness tests were performed to measure the mechanical properties. The information related to the elongation was obtained from the tensile tests. Microstructure was also studied. The experimental conditions and the measured characteristics of the welded plates are presented in Table 3 .

\section{Results}

In the experiments, the fracture occurred within the weld material as expected. The cross-section stirrer type design sweeps large amount of metal from the plasticized material and creates an inhomogeneous weld zone. Typically, the ultimate tensile strength of the weld zone is about $50 \%$ of the base metal. The fracture is expected to take place at this weak weld zone.

Five BP type ANNs were trained to represent the FSW operation. Each ANNs had six neurons in the single hidden layer. The training of the ANNs was discontinued when the $\mathrm{BP}$ reached to eight million iterations. The errors of all the networks were below $0.5 \%$ at that time. The estimations of the ANNs were compared with the actual test results by using 3-D graphs in Fig. 5. Both the 3-D plots and very small average estimation error indicated that ANNs represented the welding process adequately and may be used for searching the optimal operating conditions.

The GA searched the optimal solution according to the user's preferences by using the five ANNs. The user interface of the GONNS for inputting the preferences of the user is presented in Figs. 6 and 7. The user defined the desired search region for two input parameters and the resolution in Fig. 6. After the parameter to be minimized or maximized was selected, the ranges of all the other parameters were defined in Fig. 7. The GONNS reported the optimization results with the windows presented in Figs. 8 and 9. The displayed outputs were obtained for the same system. However, the test range was allowed for the elongation in the first optimization (Fig. 8). The GA made 4,170 iterations, and optimal tool rotation speed and the feed rates were selected as $500 \mathrm{rpm}$ and $6.25 \mathrm{~mm} / \mathrm{min}$, respectively. The range of the elongation was reduced from $3-12 \%$ to $10-12 \%$ in the second run (Fig. 9). After 1,160 iterations, GONNS changed the optimal operating conditions to $1,406 \mathrm{rpm}$ and $19.9 \mathrm{~mm} / \mathrm{min}$ to keep the elongation at the given range. In the maximized parameter, the tensile strength estimation was reduced from 112 to $80 \mathrm{MPa}$ when the acceptable elongation range was narrowed.

Table 3 Stir welding experimental results [4]

\begin{tabular}{|c|c|c|c|c|c|c|}
\hline $\begin{array}{l}\text { Tool } \\
\text { rpm }\end{array}$ & $\begin{array}{l}\text { Weld speed } \\
\mathrm{mm} / \mathrm{min})\end{array}$ & $\begin{array}{l}\text { Tensile strength } \\
(\mathrm{MPa})\end{array}$ & $\begin{array}{l}\text { Yield strength } \\
(\mathrm{MPa})\end{array}$ & $\begin{array}{l}\text { Elongation } \\
(\%)\end{array}$ & $\begin{array}{l}\text { Hardness (HV; } \\
\text { weld metal) }\end{array}$ & $\begin{array}{l}\text { Hardness (HV; } \\
\text { HAZ) }\end{array}$ \\
\hline 500 & 6.25 & 112 & 86 & 3.04 & 27.2 & 27.6 \\
\hline 500 & 10 & 104 & 80 & 3.34 & 27.5 & 28 \\
\hline 500 & 16 & 103 & 78 & 3.71 & 28 & 28.3 \\
\hline 500 & 20 & 102 & 76 & 4.78 & 28.2 & 28.5 \\
\hline 800 & 6.25 & 102 & 77 & 5.22 & 26.8 & 26.55 \\
\hline 800 & 10 & 101 & 75 & 5.44 & 27 & 26.6 \\
\hline 800 & 16 & 92 & 66 & 5.52 & 27.6 & 27 \\
\hline 800 & 20 & 91 & 65 & 5.63 & 27.8 & 27.6 \\
\hline 1,000 & 6.25 & 99 & 75 & 5.65 & 26.4 & 26 \\
\hline 1,000 & 10 & 91 & 66 & 6.36 & 26.8 & 24.8 \\
\hline 1,000 & 16 & 89 & 63 & 6.94 & 27 & 26.7 \\
\hline 1,000 & 20 & 88 & 60 & 7.63 & 27.2 & 27.2 \\
\hline 1,250 & 6.25 & 88 & 60 & 7 & 24 & 24.1 \\
\hline 1,250 & 10 & 87 & 57 & 7.02 & 24.8 & 24.8 \\
\hline 1,250 & 16 & 86 & 56 & 7.36 & 25.7 & 25.3 \\
\hline 1,250 & 20 & 84 & 53 & 8.36 & 26.1 & 25.9 \\
\hline 1,500 & 6.25 & 80 & 58 & 7.45 & 21.4 & 23.4 \\
\hline 1,500 & 10 & 79 & 86 & 10.17 & 22 & 23.7 \\
\hline 1,500 & 16 & 77 & 52 & 10.39 & 22.9 & 24.8 \\
\hline 1,500 & 20 & 76 & 47 & 11.26 & 23.8 & 25.2 \\
\hline
\end{tabular}




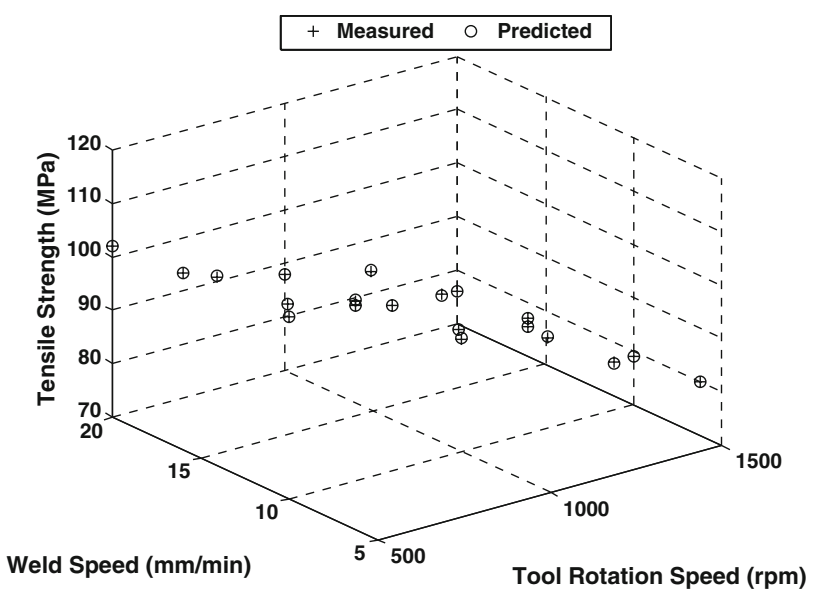

(a) Tensile Strength (MPa)

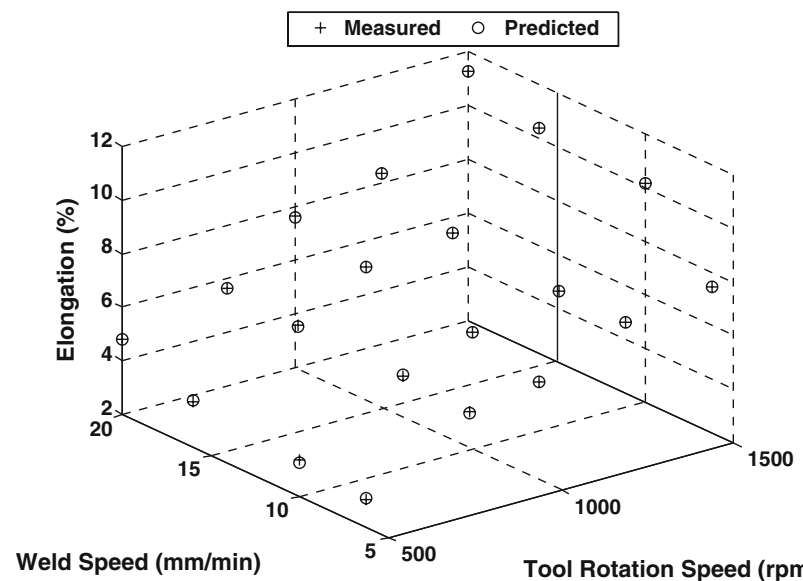

(c)

Elongation (\%)

Tool Rotation Speed (rpm) Weld Speed ( $\mathrm{mm} / \mathrm{min}$ )

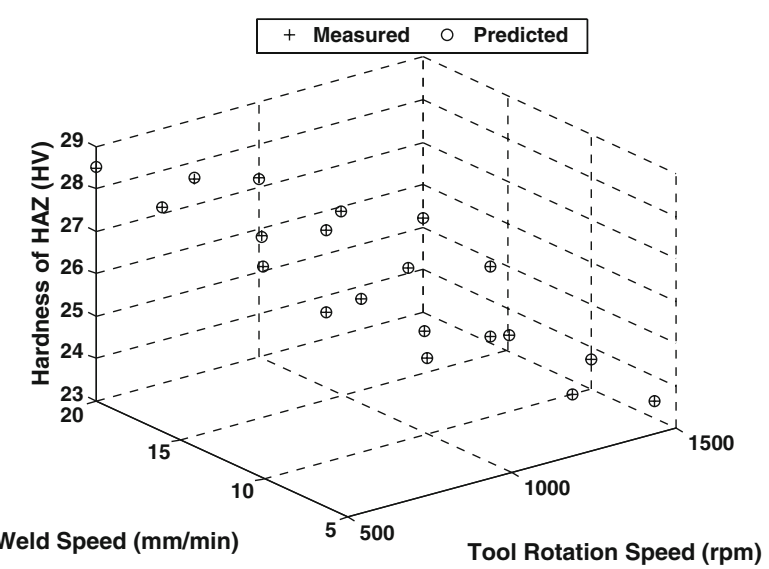

(d) Hardness of HAZ (HV)

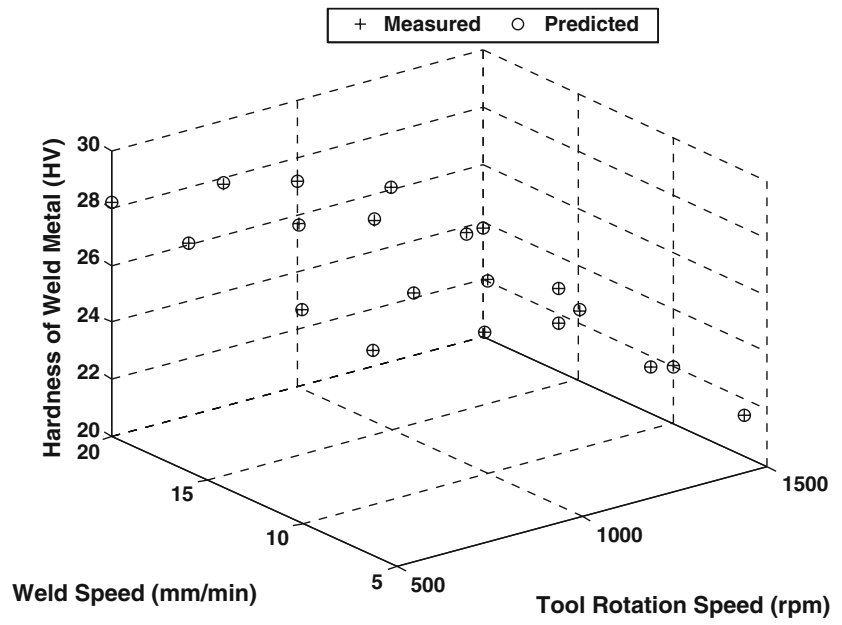

(e) Hardness of welded metal (HV)

Fig. 5 Comparison of the estimations of the artificial neural network with the characterization results. a Tensile strength (MPa). b Yield strength (MPa). c Elongation (percent). d Hardness of HAZ (HV). e Hardness of welded metal (HV) 


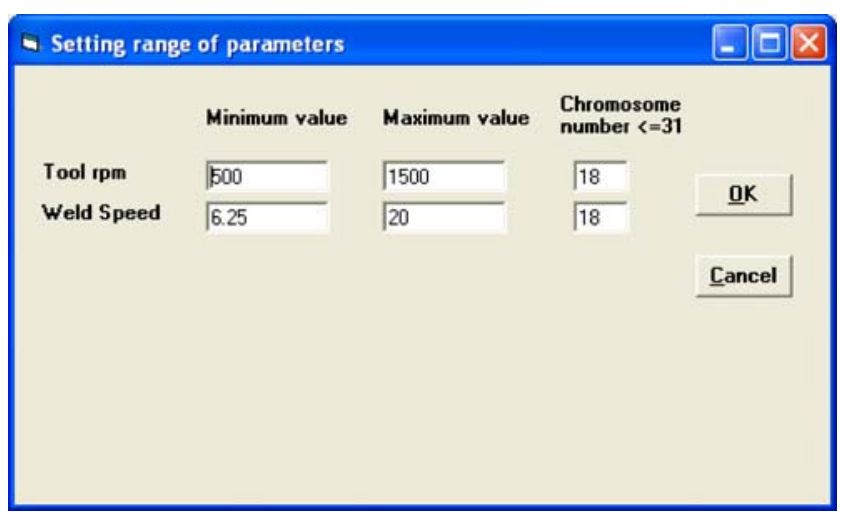

Fig. 6 The user interface of the genetically optimized neural network system to determine the search region and resolution

\section{Conclusion}

Representations of the characteristics of FSW operation by using ANNs and selection of the optimal tool rotation speed and feed rate (weld speed) by using the GA were proposed. The in-house developed GONNS package was used for modeling and optimization. The package first trained the ANNs with experimental data. Later, the GA estimated the optimal parameters.

The performance of the GONNS was found to be a viable option for modeling the stir welding process and searching for the optimal solutions. One ANN was assigned to each one of the considered five performance parameters of the welding zone: tensile strength, yield

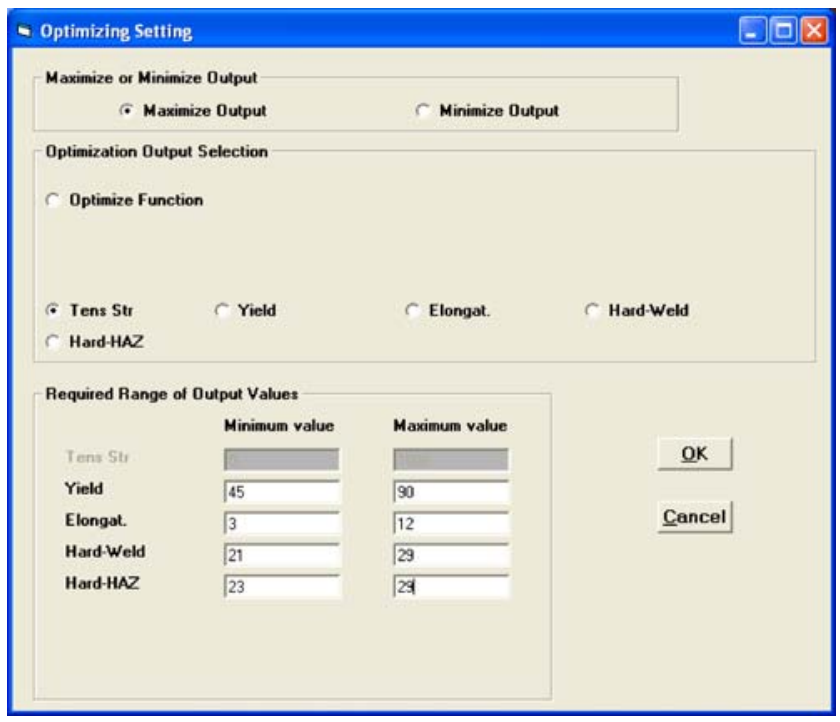

Fig. 7 The user interface of the genetically optimized neural network system for selection of the parameter to be minimized or maximized and the acceptable range of the parameters

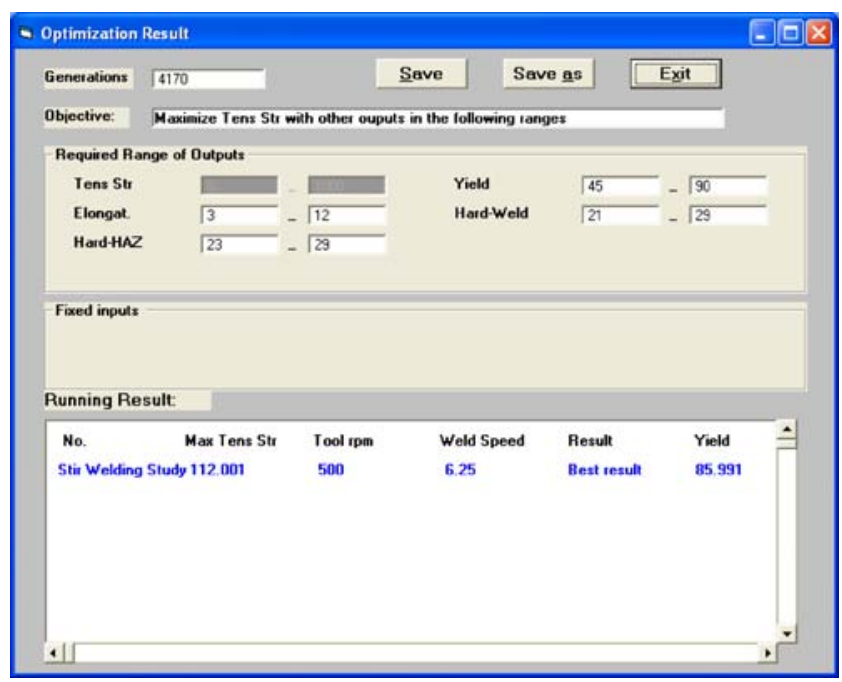

Fig. 8 The optimization result when all the output parameters were allowed to stay in their full range presented

strength, elongation (percent), hardness of weld metal, and hardness of heat-affected zone. The inputs of the five ANNs were the same (tool rotation and welding feed rate). The estimation errors of the ANNs were better than average $0.5 \%$. GA estimated the optimal FSW conditions to minimize or maximize one of the stir welding characteristics, while the others were kept at the desired ranges.

The GONNS may model many systems if experimental data or a series of observations are available. The ANN-GA combination of the GONNS performed as expected in this application and is recommended for others.

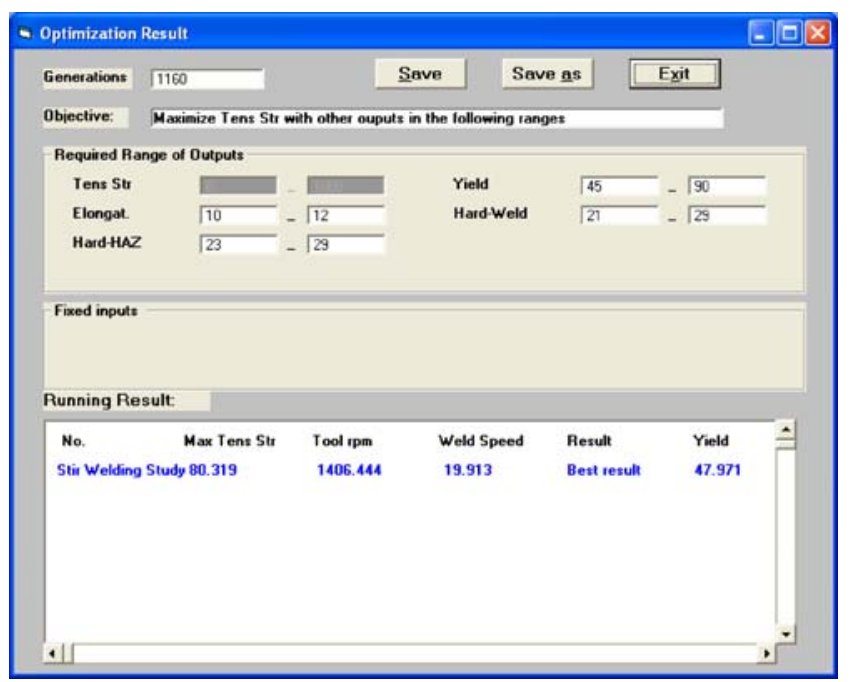

Fig. 9 The optimization result when the acceptable elongation range was reduced to $10 \%$ to $12 \%$ 
Open Access This article is distributed under the terms of the Creative Commons Attribution Noncommercial License which permits any noncommercial use, distribution, and reproduction in any medium, provided the original author(s) and source are credited.

\section{References}

1. Sato YS, Sugiura Y, Shoji Y, Park SHC, Kokawa H, Ikeda K (2004) Post-weld formability of friction stir welded Al alloy 5052. Mater Sci Eng A 369:138-143

2. Mandal S, Williamson K (2006) A thermomechanical hot channel approach for friction stir welding. J Mater Process Technol 174:190-194

3. Paglia CS, Jata KV, Buchheit RG (2006) A cast 7050 friction stir weld with scandium: microstructure, corrosion and environmental assisted cracking. Mater Sci Eng A 424:196-204

4. Okuyucu H, Kurt A, Arcaklioglu E (2007) Artificial neural network application to the friction stir welding of aluminum plates. Mater Des 28:178-184

5. Zhoua C, Yang X, Luan G (2006) Investigation of microstructures and fatigue properties of friction stir welded $\mathrm{Al}-\mathrm{Mg}$ alloy. Mater Chem Phys 98:285-290

6. Kulekci MK, Şik A, Kaluç E (2008) Effects of tool rotation and pin diameter on fatigue properties of friction stir welded lap joints. Int J Adv Manuf Technol 36:877-882

7. Chen C, Kovacevic R, Jandgric D (2003) Wavelet transform analysis of acoustic emission in monitoring friction stir welding of 6061 aluminum applied to friction stir welded steel. Int J Mach Tools Manuf 43:1383-1390

8. Prado RA, Murr LE, Soto KF, McClure JC (2003) Selfoptimization in tool wears for friction-stir welding of Al 6061_ 20\% A12O3 MMC. Mater Sci Eng A 349:156-165

9. Fernandez GJ, Murr LE (2004) Characterization of tool wear and weld optimization in the friction-stir welding of cast aluminum $359+20 \% \mathrm{SiC}$ metal-matrix composite. Mater Charact 52:65-75

10. Buffa G, Hua J, Shivpuri R, Fratini L (2006) Design of the friction stir welding tool using the continuum based FEM model. Mater Sci Eng A 419:381-388

11. Zhang Z, Zhang HW (2007) Material behaviors and mechanical features in friction stir welding process. Int J Adv Manuf Technol 35:86-100

12. Zhou C, Yang X, Luan G (2006) Effect of root flaws on the fatigue property of friction stir welds in 2024-T3 aluminum alloys. Mater Sci Eng A 418:155-160

13. Ouyang J, Yarrapareddy E, Kovacevic R (2006) Microstructural evolution in the friction stir welded 6061 aluminum alloy (T6temper condition) to copper. J Mater Process Technol 172:110-122

14. Heurtier P, Jones MJ, Desrayaud C, Driver JH, Montheillet F, Allehaux D (2006) Mechanical and thermal modelling of friction stir welding. J Mater Process Technol 171:348-357

15. Czechowski M (2005) Low-cycle fatigue of friction stir welded Al-Mg alloys. J Mater Process Technol 164-165:1001-1006

16. Sato YS, Nelson TW, Sterling CJ, Pettersson CO (2005) Microstructure and mechanical properties of friction stir welded
SAF 2507 super duplex stainless steel. Mater Sci Eng A 397:376384

17. Jones MJ, Heurtier P, Desrayaud C, Montheillet F, Allehaux D, Driver JH (2005) Correlation between microstructure and microhardness in a friction stir welded 2024 aluminium alloy. Scripta Mater 52:693-697

18. Chen CM, Kovacevic R (2004) Joining of Al 6061 alloy to AISI 1018 steel by combined effects of fusion and solid state welding. Int J Mach Tools Manuf 44:1205-1214

19. Liu HJ, Fujii H, Maeda M, Nogi K (2003) Tensile properties and fracture locations of friction-stir-welded joints of 2017-T351 aluminum alloy. J Mater Process Technol 142:692-696

20. Rumelhart DE, Hilton G, Williams RJ (1986) Learning internal representations by error propagation. In: Rumelhart E, McClelland JL (eds) Parallel distributed processing: explorations in the microstructure of cognition, vol 1. MIT Press, Cambridge, MA

21. Dayhoff JE (1990) Neural network architectures: an introduction. Van Nostrand Reinhold Co., New York, NY

22. Hecht-Nielsen R (1990) Neurocomputing. Addison-Wesley Publishing Company, Massachusetts, USA

23. DARPA (1988) Neural network study. AFCEA International Press, Fairfax

24. Chryssolouris G, Domroese M, Beaulieu P (1992) Sensor synthesis for control of manufacturing processes. J Eng Ind Trans ASME 114:158-174

25. Tansel IN (1990) Neural network approach for representation and simulation of 3D-cutting dynamics. Trans North Am Met Res Inst, 18:193-200

26. Tansel I, Bao WY, Arkan TT, Tansel B (1997) Visualization of underground contamination by using neural networks, smart engineering system design: neural networks, fuzzy logic, and evolutionary programming. ASME Press, New York

27. Masters T (1995) Advanced algorithms for neural networks. Wiley, New York

28. Goldberg DE (1989) Genetic algorithms in search. Optimization and machine learning. Addison-Wesley, Reading, MA

29. Carroll DL (1996) Chemical laser modeling with genetic algorithms. AIAA J 34:338-346

30. Winter G, Cuesta P, Periaux J et al (1996) Genetic algorithm in engineering and computer science. Wiley, New York

31. Tansel IN, Ozcelik B, Bao WY, Chen P, Rincon D, Yang SY, Yenilmez A (2006) Selection of optimal cutting conditions by using GONNS. Int J Mach Tools Manuf 46:26-35

32. Tansel IN, Yang SY, Shu C, Bao WY, Mahendrakar N (1999) Introduction to genetically optimized neural network systems (GONNS). Smart engineering systems: neural networks, fuzzy logic, evolutionary programming, data mining, and rough sets. ASME Press, New York, pp 331-336

33. Yang SY, Tansel IN, Kropas-Hughes CV (2003) Selection of optimal material and operating conditions in composite manufacturing part I: computational tool. Int J Mach Tools Manuf 43:169-173

34. Yang SY, Girivasan V, Singh NR, Tansel IN, Kropas-Hughes CV (2003) Selection of optimal material and operating conditions in composite manufacturing. Part II: complexity representation of characteristics and decision making. Int $\mathrm{J}$ Mach Tools Manuf $43: 175-184$ 